عبدالناصر صبحي

تجارة النفطوأثرها في تلوث الخليج العربي

$$
\text { عبدالناصر صبحي إبراهيم العمري }
$$

مدرس مساعد، كلية الإدارة والاقتصاد، جامعة الموصل

$$
\text { مستخلص البحث }
$$

تعد مذطقة الخليج العربي من أهم المراكز لإنتاج النفط وخـزين سـتراتيجي عـالمي، ممـا جعلـها مسن أكثر المناطق تلوثا في العالم، إذ يسبب هذا التلوث أثـار فادحسة في الإنسـان والحيـوان، ولقــ تم التصدي

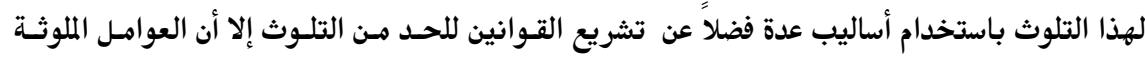

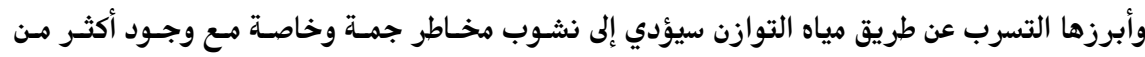
57\% من احتياطي النفط للعالم في بلدان الخليج العربي.

المقدمة

تمثل تجارة النفط العمود الفقري لاقتصاديات البلدان المطلة على الخليج العربي اذ تمثل السلعة الرئيسة من صادراتها، ويصدر من الخليج العربي أكثر مسن ثلث صـادرات الـنفط في العالم فانعكس هذا بدوره في تلوث خطير لمياه الخليج العربي ومن ثم الضرر بصدة الإنسـان وبحياة الطبيعية التي أوجدها اللّه وسخرها سبحانه وتعالى لخدمة الإنسان، قال تعالى (وَهُوَ

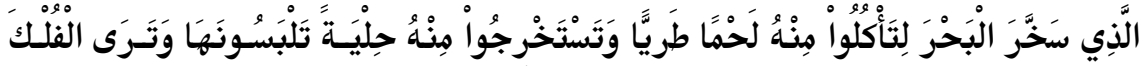

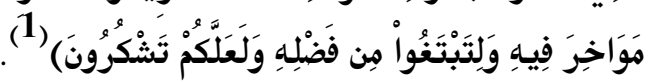
أهمية البحث تتمثل في دراسة اثر التلوث والتكاليف المحتملة لعلاجه في ضوء المخزونات النفطية لدى بلدان الخليج العربي. وتتمثل مشكلة البحث بارتفـاع نسبة التلـوث في الخليج العربي التي تؤثر في الكائنات الحية، كما يهدف البحث إلى معرفة حجم تأثير تجارة الـنفط في تلوث الخليج العرب، واستند البحث على فرضية إن تجارة النفط تتسبب بآثار سلبية في تلوث الخليج العربي، واعتمد البحث على الإطسار التحليلي الوصفي ضـمن أربعـة مباحـث تضمن الأول مميزات الخليج العربي وأهمية تجارة الـنفط بالنسـبة لإجمسالي صـادرات بلـدان الخليج العربي وتناول المبحث الثاني مصادر التلوث ومخاطره في مياه الخليج العربسي واهـتم 
المبحث الثالث بمعالجة التلوث والاتفاقيات العالمية والمحليـة المتعلقـة بهـذا الشـأن وخلـص

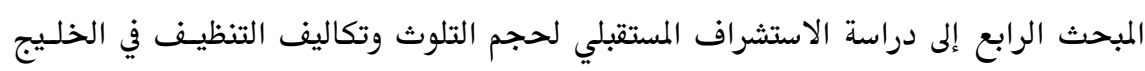
العربي.

المبحث الأول : مميزات الخليج العربي وأهمية تجارة الـنفط بالذسبة لإجمـالي صـادرات بلدان الخليج العربي يتميز الخليج العربي بعدة مميزات تجعله من اشد المنـاطق تلوثـاً إذ يعـد حوضـاً صـغيراً

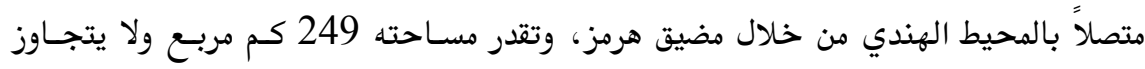

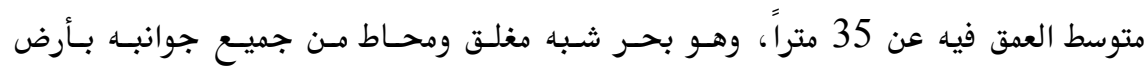

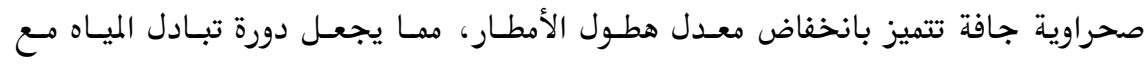

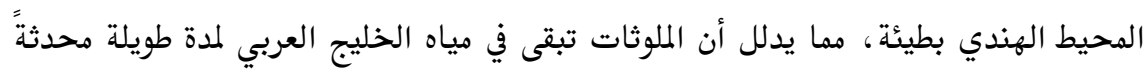

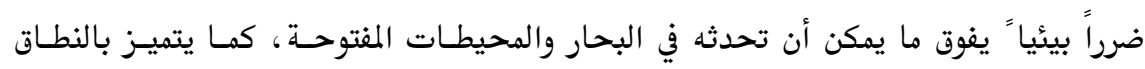

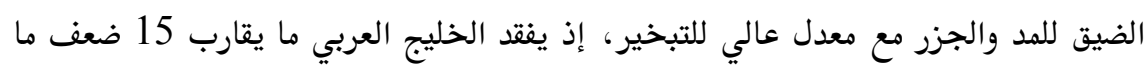

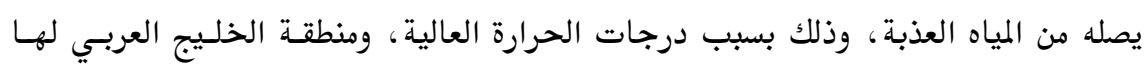

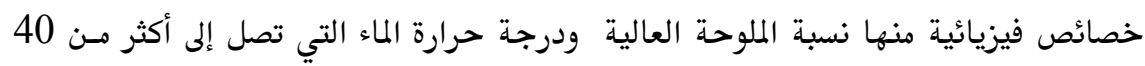

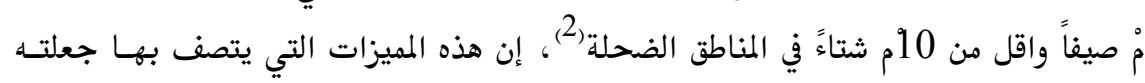
من اكبر المناطق تلوثا في العالم إذ تزيد نسبة التلوث فيه عن 48 مرة عن أي منطقة مشـابهة الضحة

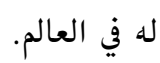

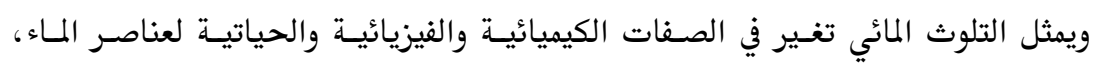

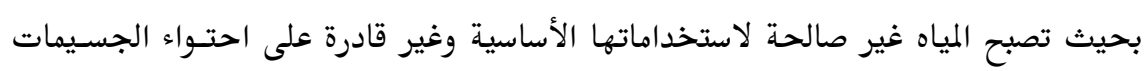

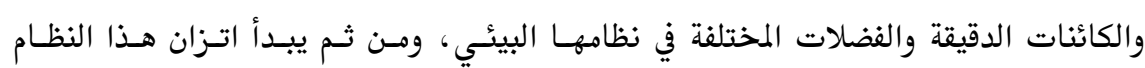
بالاختلال حتى يصل إلى الحد الحرج والذي تبدأ معه الآثار الضارة بالظهور في البيئة.

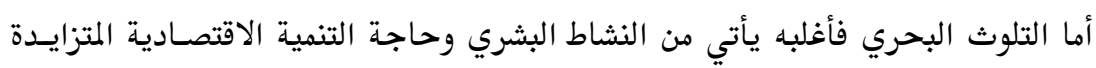

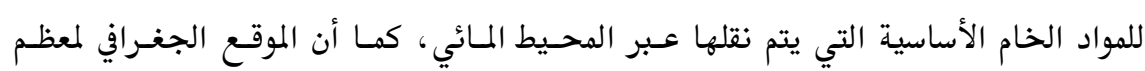

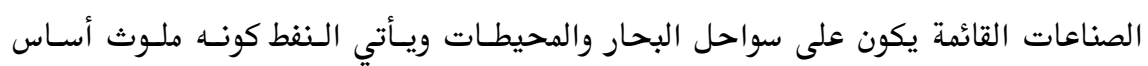




$$
\text { عبدالناصر صبحي }
$$

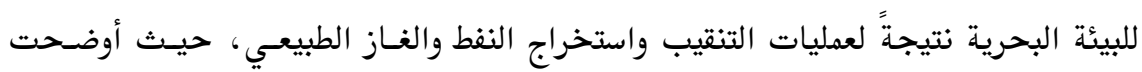

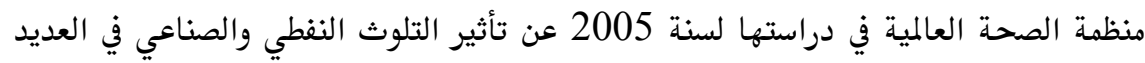

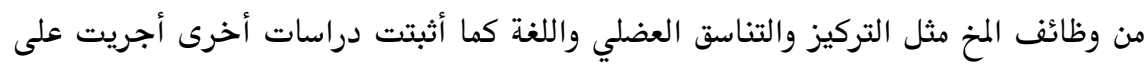

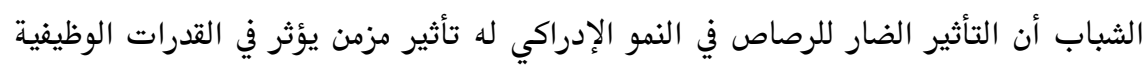

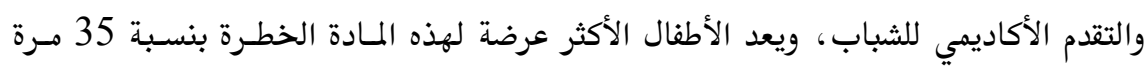

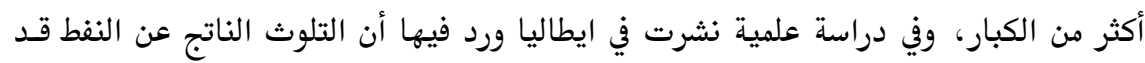

$$
\text { يؤثر في خصوبة الرجال (3). }
$$

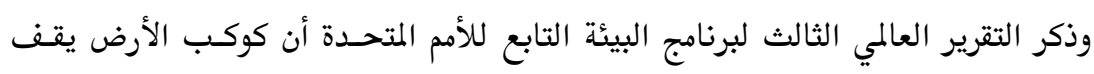

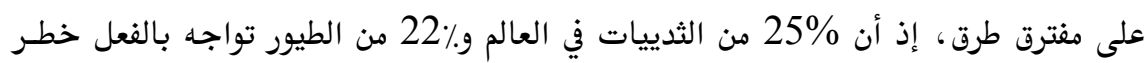

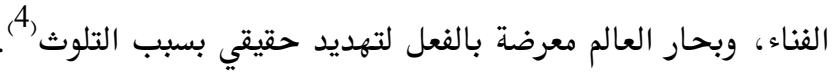
ولكي نعلم مدى الخطر الذي تواجهه البلدان العربية من جراء التلوث وخاصة في الخليج

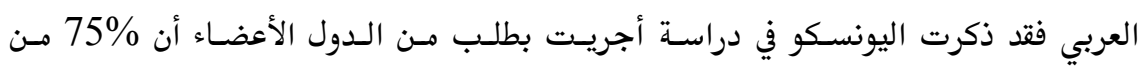

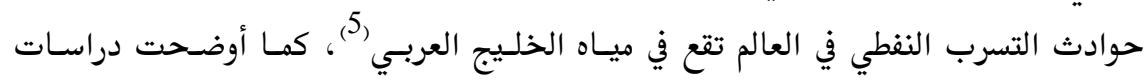

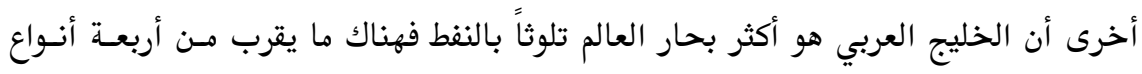

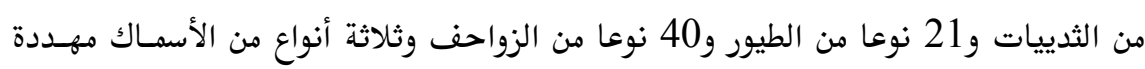
بالانقراض تماماً (6). ويتبين أهمية تجارة النفط بالنسبة لإجمالي صـادرات بلـدان الخلـيج العربي مسن خـلال اعتماد هذه البلدان على سلعة واحدة رئيسية متمثلة بالنفط حيث تمثل لـبعض هـذه البلدان

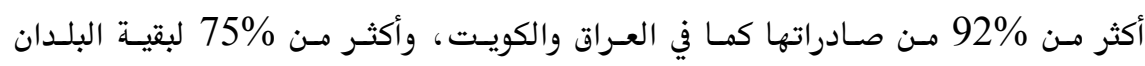

$$
\text { الأخرى(7) كما في الجدول (1). }
$$

الجدول (1) أهمية صادرات النفط بالنسبة لإجمالي الصادرات لسنة 2009 مليار دولار 


\begin{tabular}{|c|c|c|c|}
\hline نالى إجمالي الصادرات & قيمة إجمالي الصادرات & قيمة صادرات النفط & اسم البلد \\
\hline 33,3 & 174,725 & 58,201 & الامارات \\
\hline 89,7 & 175,529 & 157,407 & السعودية \\
\hline 94,3 & 44,373 & 41,852 & العراق \\
\hline 80,7 & 33,256 & 26,840 & قطر \\
\hline 92,7 & 50,243 & 46,569 & الكويت ل \\
\hline 78,8 & 70,614 & 55,604 & ايران \\
\hline
\end{tabular}

المصدر

OPEC, Annual statistical Bulletin, 2009, p. 16-17

W T O, International Trade Statistics, 2010, p.59

$$
\text { المبحث الثاني: مصادر التلوث ومخاطره في مياه الخليج العربي }
$$

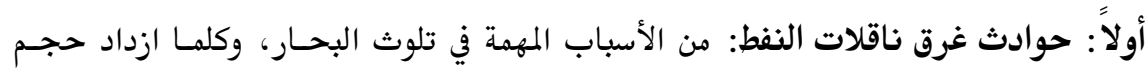

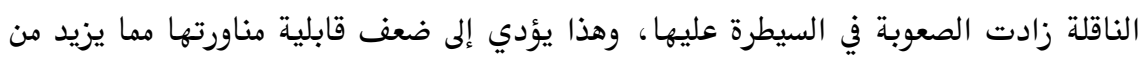

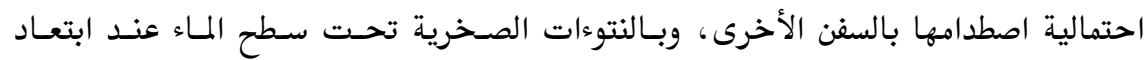

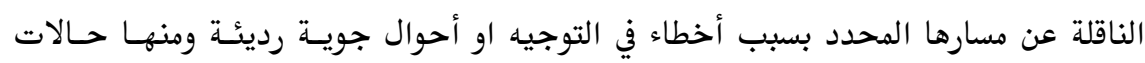

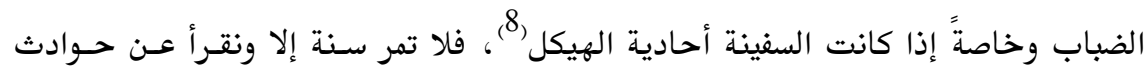

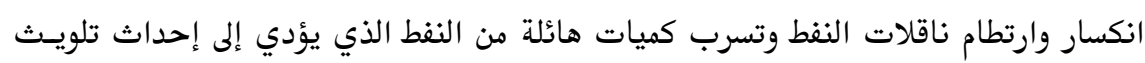

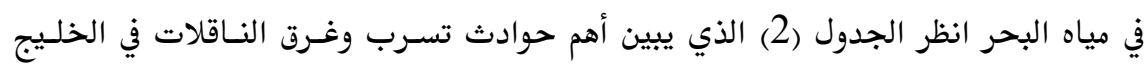
العربي.

\begin{tabular}{|c|c|c|c|}
\hline الحمولة/برميل & السنة & منطقة الغرق & اسم الناقلة \\
\hline 105000 & 1971 & الخليج العربي & ايران البحرية \\
\hline
\end{tabular}




\begin{tabular}{|c|c|c|c|}
\hline 842950 & 1972 & خليج عمان & نجمة البحر \\
\hline 266700 & 1979 & الإمارات العربية المتحدة & باتيانا \\
\hline 40000 & 1980 & مقابل دبي & فورتون \\
\hline 6714 & 1980 & مقابل البحرين & جريمونا - \\
\hline 376200 & 1983 & خليج عمان & 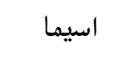 \\
\hline 333000 & 1983 & 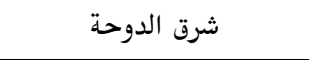 & 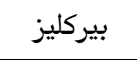 \\
\hline 521500 & 1985 & قبالة جزر إيران & نوفا \\
\hline 1833 & 1989 & 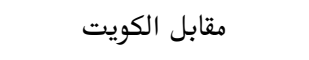 & انتر براس \\
\hline 119048 & 1994 & مقابل سواحل الفجيرة & 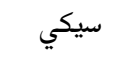 \\
\hline 733000 & 1998 & قبالة عجمان & بانتون \\
\hline الحمولة/برميل & السنة & 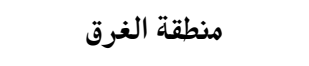 & اسم الناقلة \\
\hline غير معلومة & 1999 & ق قبالة الفجيرة & 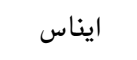 \\
\hline 7183 & 2000 & مقابل ابو ظبي & 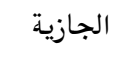 \\
\hline 9529 & 2001 & بالقرب من جبل علي بدبي & 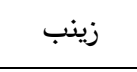 \\
\hline 13927 & 2001 & قرب السواحل الكويتية & جورجويس \\
\hline
\end{tabular}

المصدر: جمعت بالاعتماد على المصادر الاتية:

-Oil spill intelligence report international oil spill database: international oil spill conference, 1997, p.950

-www.iose, org/papers/01480, pdf

-Oil tanker spill statistics: 2009 , p.5

www, Itopf , com-

-www.marinergroup.com/oil-spill-history.htm

ثانيا: انفجار الحقول النفطية: يضم الخليج العربي حقولاً عـدّة في داخـل مياهـه ممـا أدى إلى قيام أبار نفطية تعمل على إنتاج النفط بكميات كبيرة وهي معرضة باستمرار إلى حـوادث بسبب العواصف وأخطاء تقنيّة مما يؤدي إلى تسرب النفط منهـا، كمـا حسدث عنـدما انفجـر 
احد الحقول النفطية البحرية في السعودية سنة 1981 والذي أدى إلى تسرب أكثر مـن 80 ألف برميل وكون بقعة زيتية بلغ طولها 95 كم وصلت إلى الشواطئ القطرية والبحرينية (9.

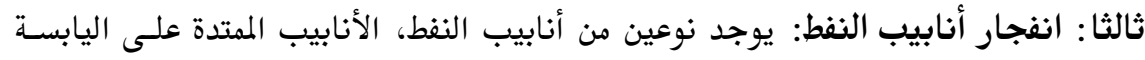

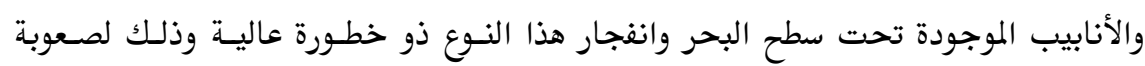

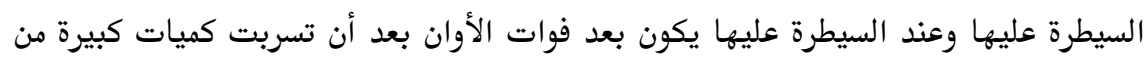

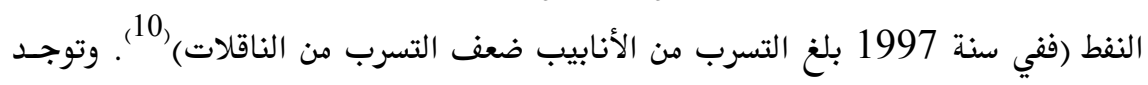

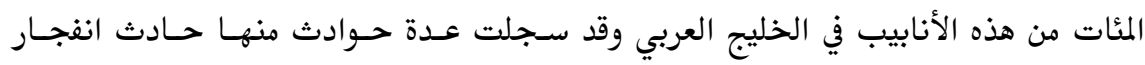

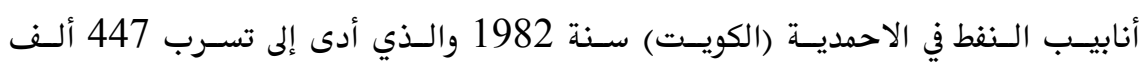
برميل (11). رابعاً: العمليات الحربية: : تعد ذات اثر واضح في تلوث الخليج العربي واتضح ذلك جليـاً

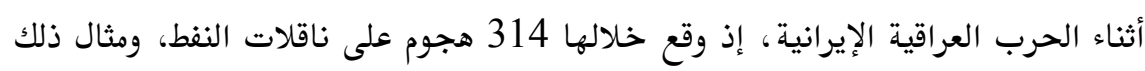

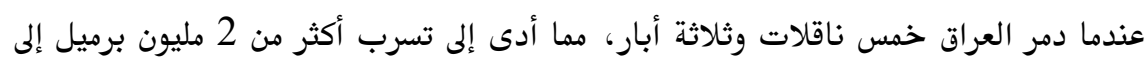

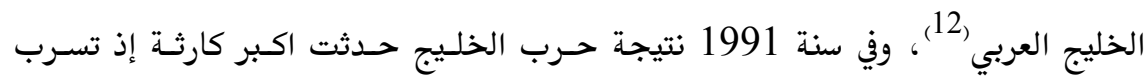

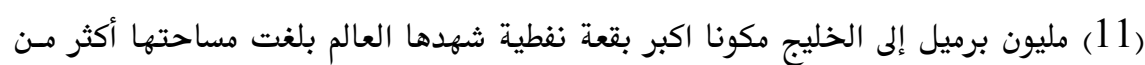

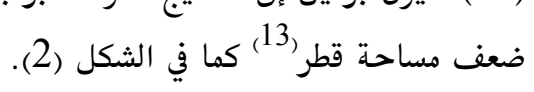
خامساً: الإهمال: يصاحب مراحل فرل إنتاج النفط من حفر واستخراج وتكرير وتصدير حسوادث

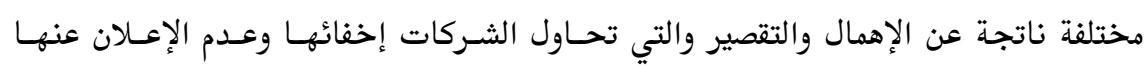

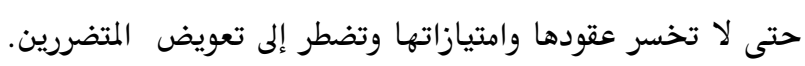

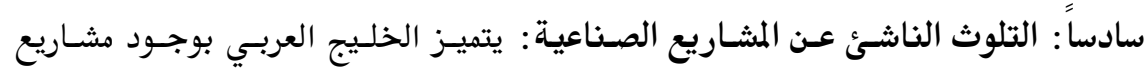

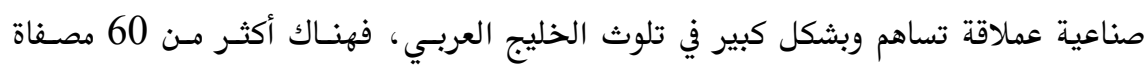

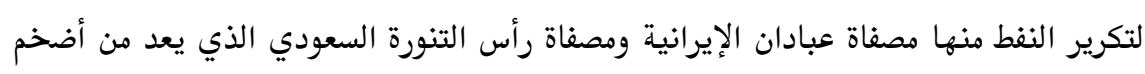

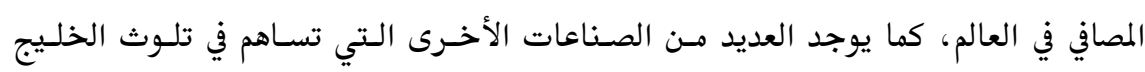

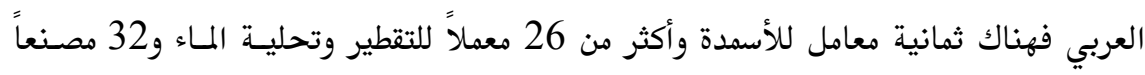

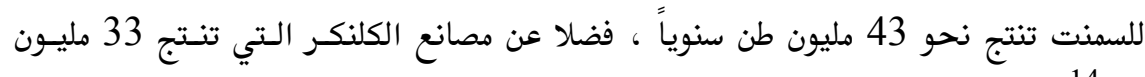

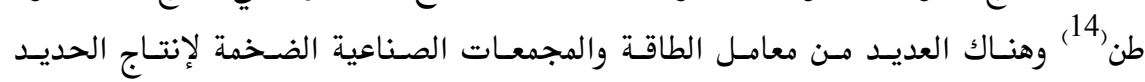


والصلب والألمنيـوم والنحساس، وتقدير كميـة الـنفط المتسـربة نتيجـة عمليـات تكريـر الـنفط

$$
\text { والصناعات البتروكيمياوية بـ 13\% من إجمالي النفط المتسرب. }
$$

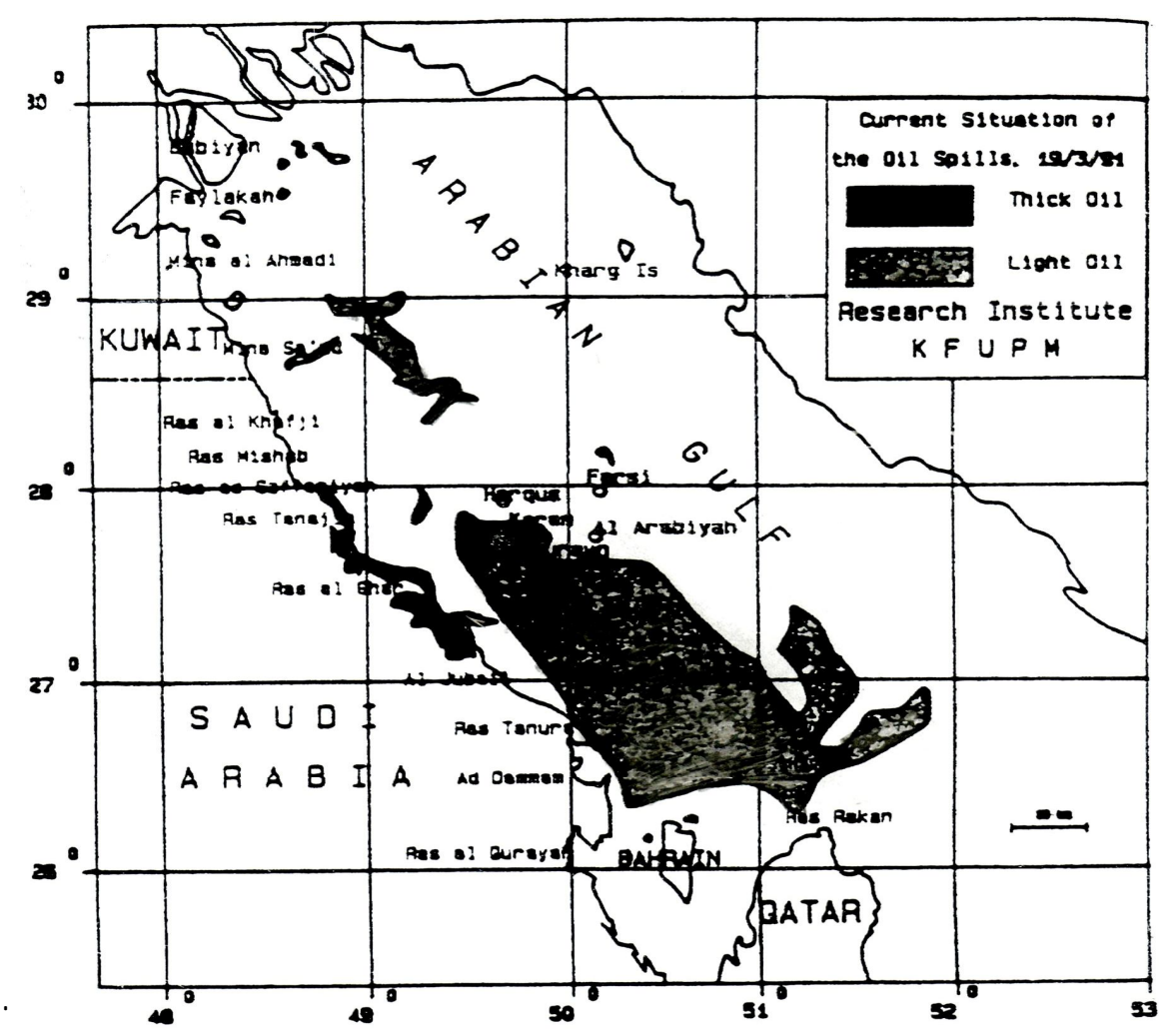

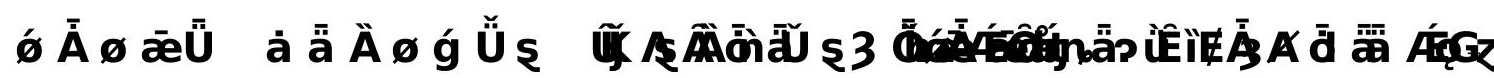

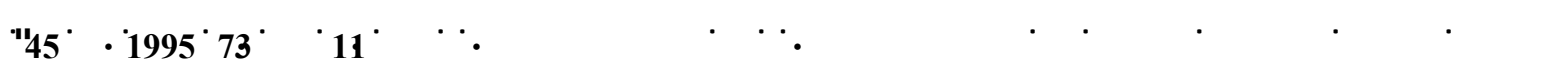




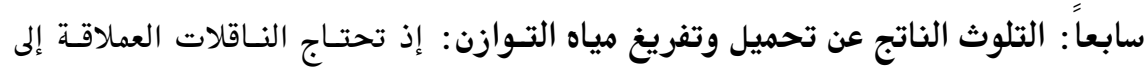
حفظ توازنها بعد أن تفرغ حمولتها من النفط ومنتجاته فتسـتعمل ميساه البحـر للحفـاظ على تلى توازنها لتستعمله (كثقل) وبعد مغادرتها تفرغ حمولتها من هذه الميساه الملوثـة في ميـاه البحـر

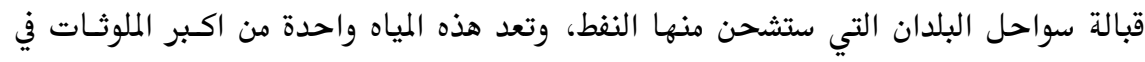
الخليج العربي إذ أن كل ناقلة تقذف 1\% من حمولتها من من النفط إلى الخليج، وبما أن إنتاج

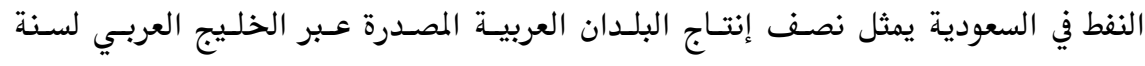

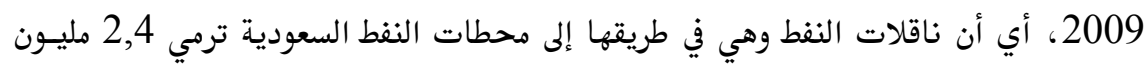

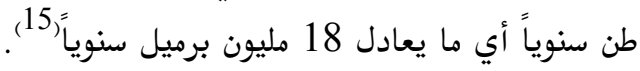

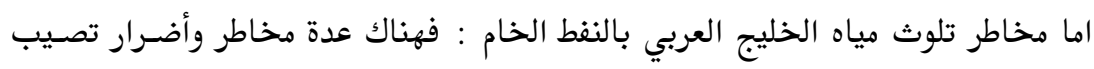

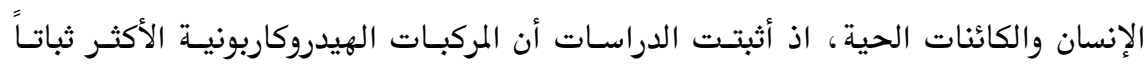

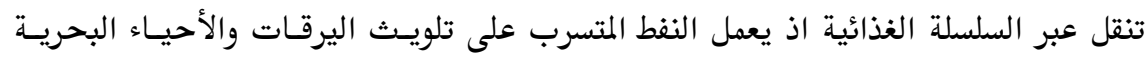

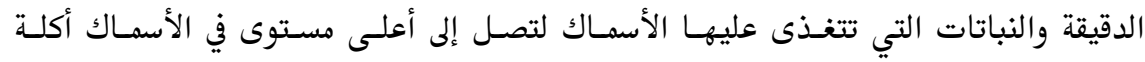

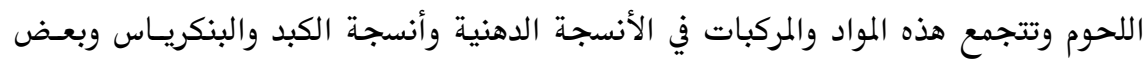

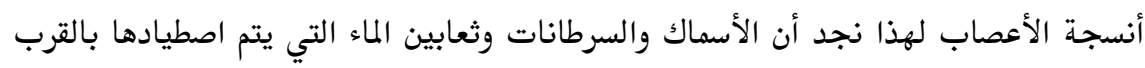

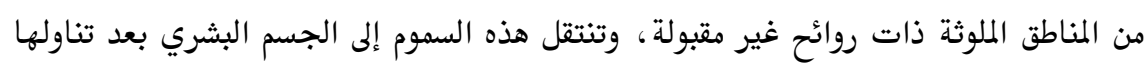

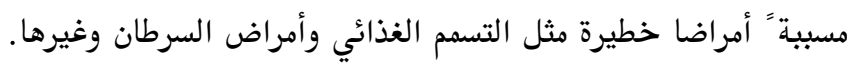

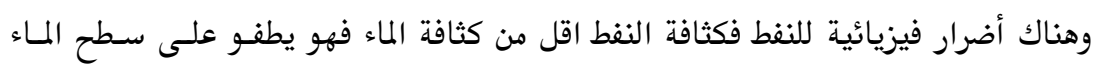

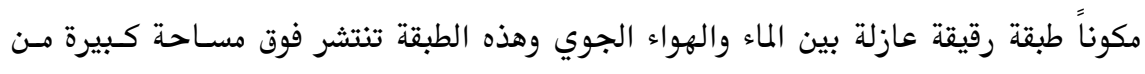

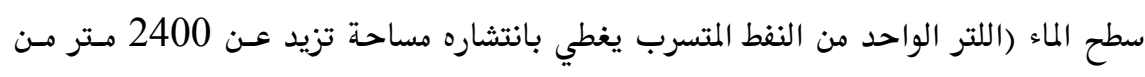

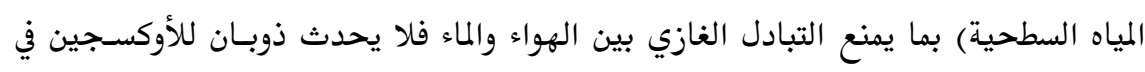

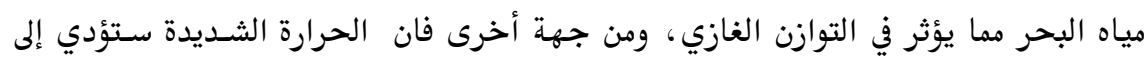

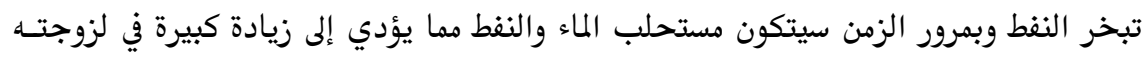

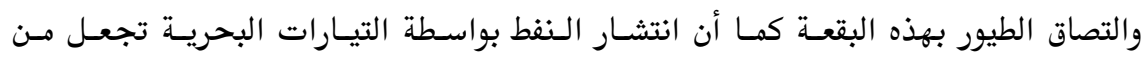




$$
\text { عبدالناصر صبحي }
$$

الصعوبة استعادته مما يؤدي إلى انتقاله إلى السواحل التي يعمل على تلويثها فضلا عن انغمار

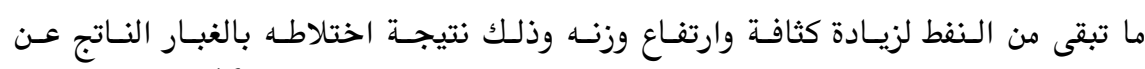
العواصف الترابية القادمة من المناطق الصحراوية المحيطة بالخليج العربي (16).

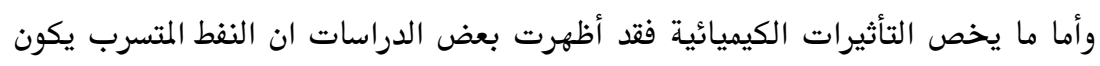

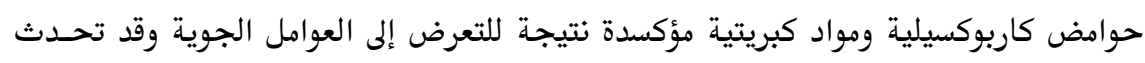

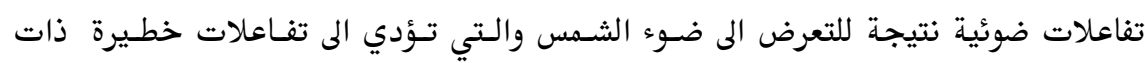

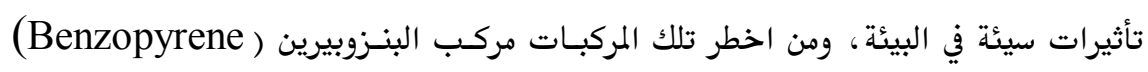

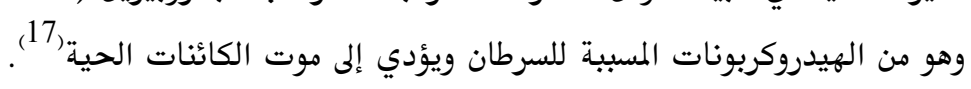

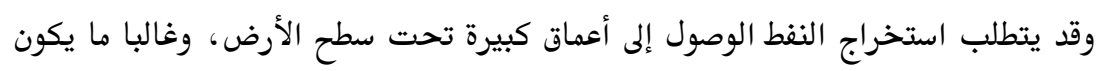

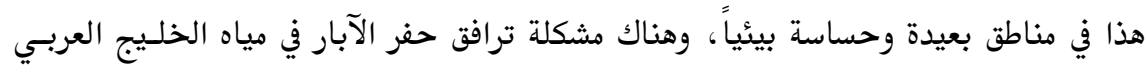

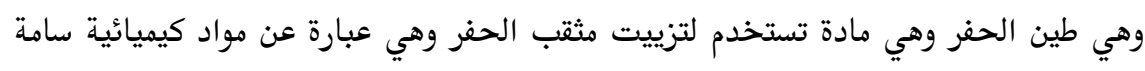

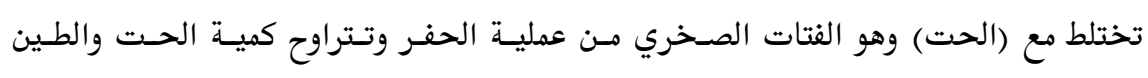

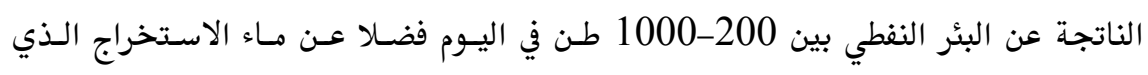

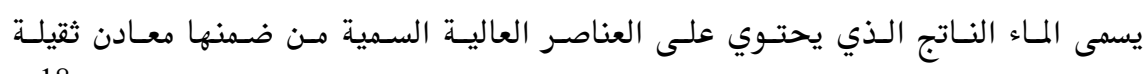

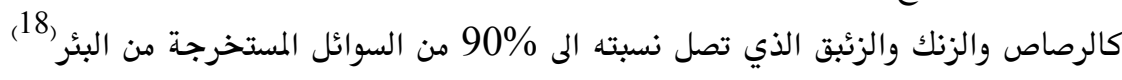

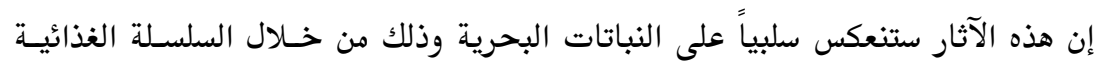

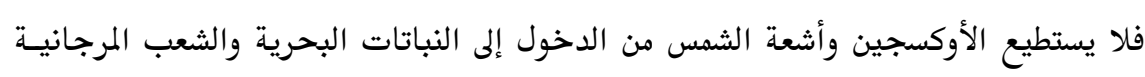

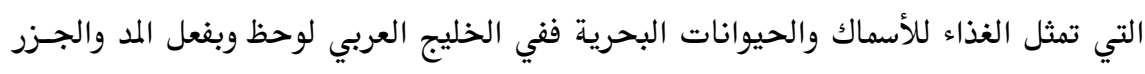

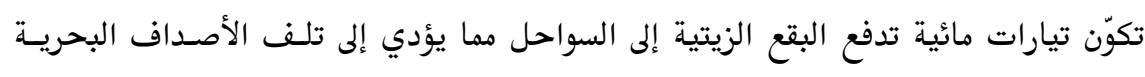

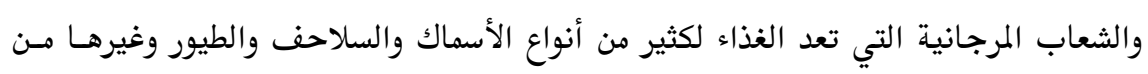

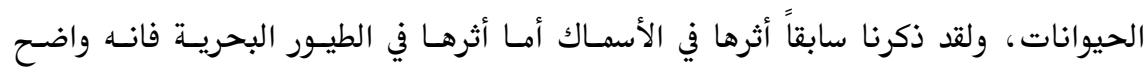

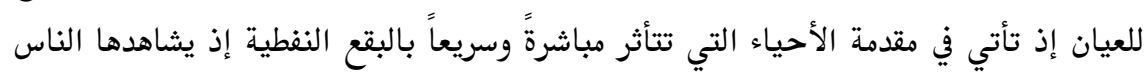

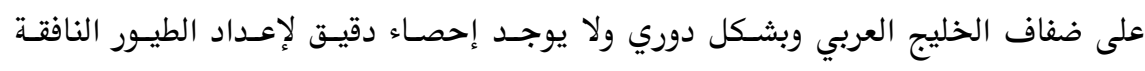

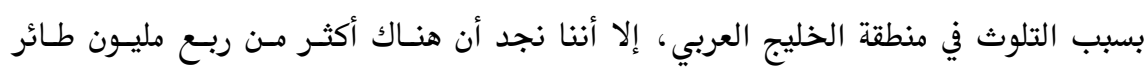

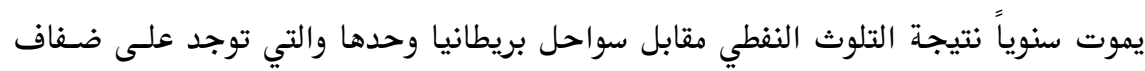


الشواطئ وهي أرقام اقل من الواقع بسبب مـوت كثير منهـا في عـرض البحـر ولاتصـل إلى

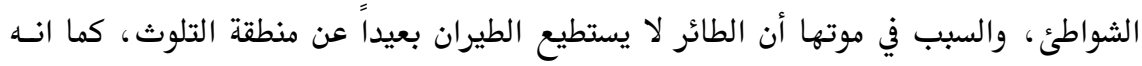

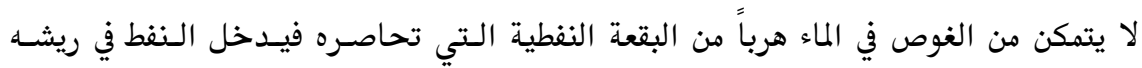

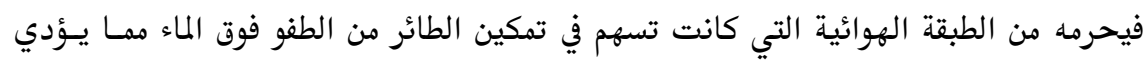

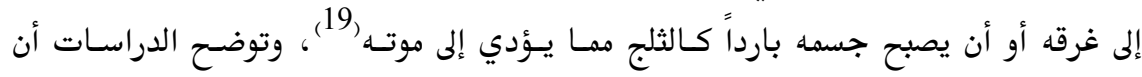

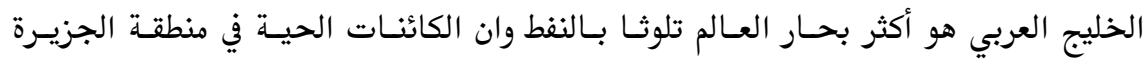
العربية ههددة بالانقراض فهناك أربعة أنواع من الثدييات و21 نوعاً مـن الطيـور و40 نوعـاً من الزواحف وثلاثة أنواع من الأسماك مهددة بالانقراض تماماً 20.

المبحث الثالث: معالجة التلوث والاتفاقيات العالمية والمحلية المتعلقة بهذا الشأن

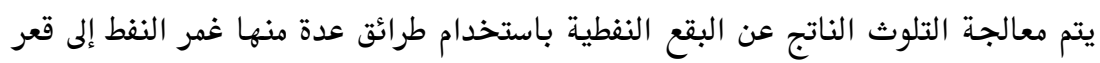

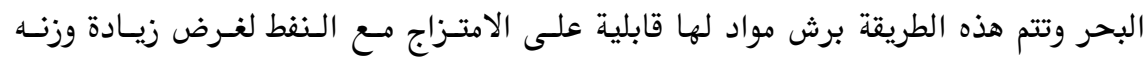

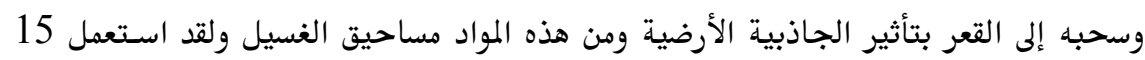

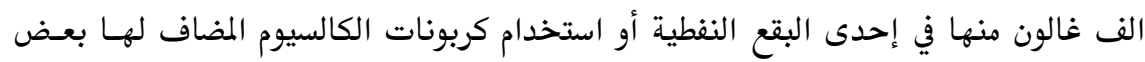

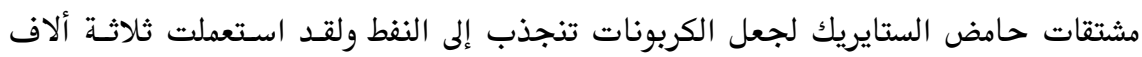

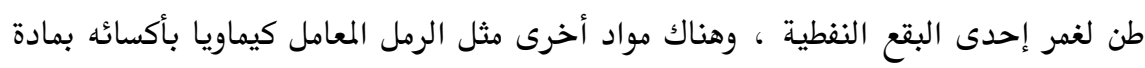

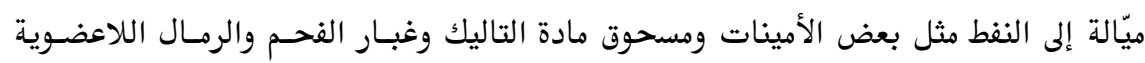

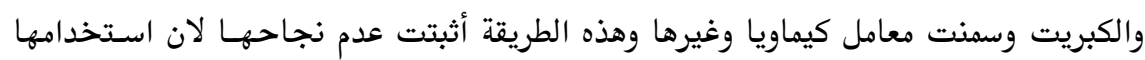

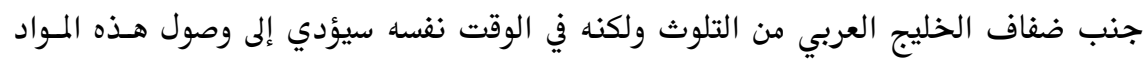

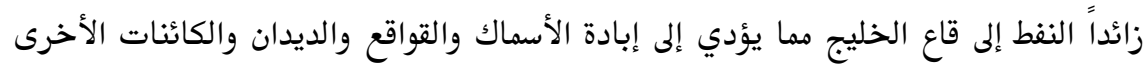

$$
\text { التي تعيش في قعر الخليج. }
$$

ولهذا تم استخدام طريقة أخرى وهي حرق النفط على سـطح البحـر اذ يـتم حسرق الـنفط

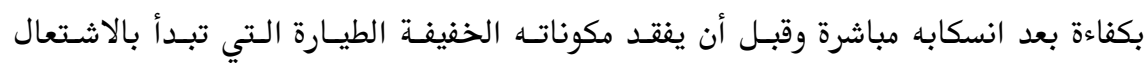

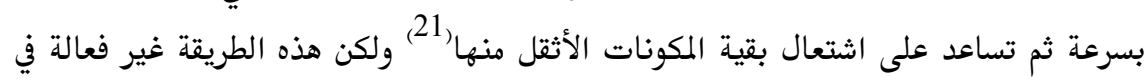

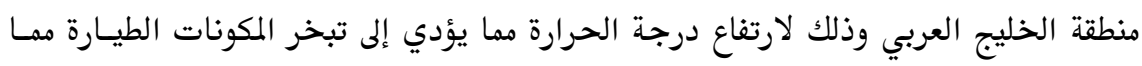




$$
\text { عبدالناصر صبحي }
$$

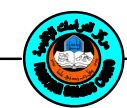

تجارة النفط وأثرها في ثلوث الخليج

يستدعي إضافة مواد مساعدة للاشتعال والمشكلة الأخرى لهذه الطريقـة هي استبدال تلـوث

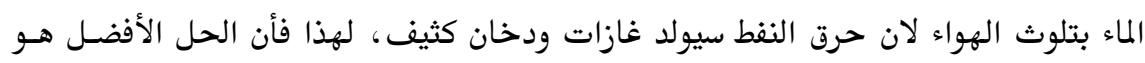

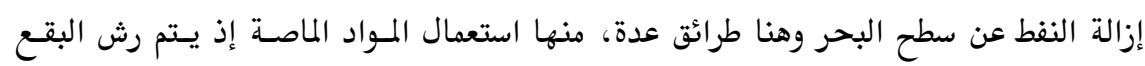

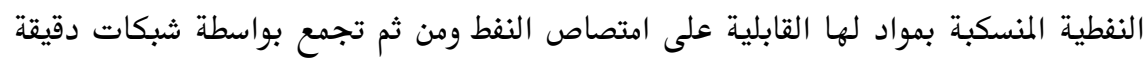

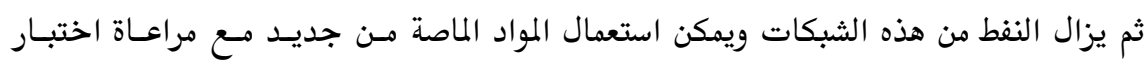

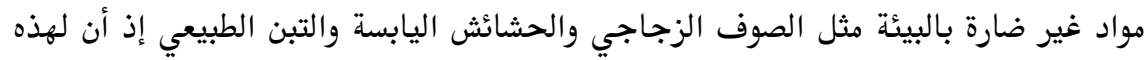

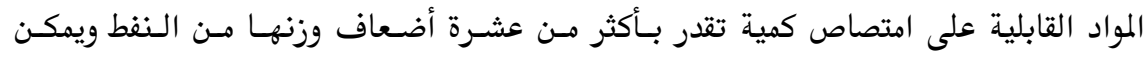

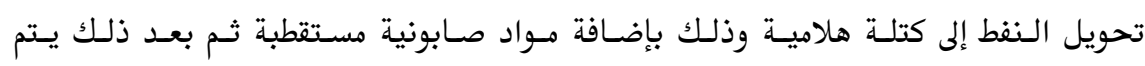
تجميعها.

وهناك طريقة أخرى ذات فاعلية كبيرة ولا تضر بالبيئة وهي عملية تطويق البقعة النفطية

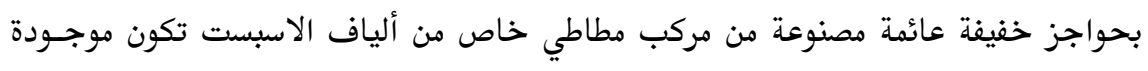

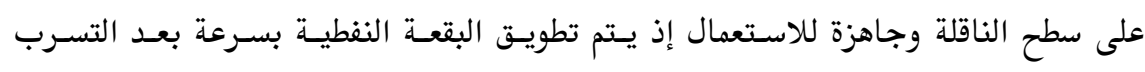

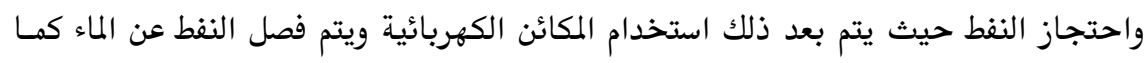

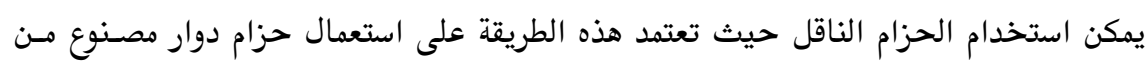

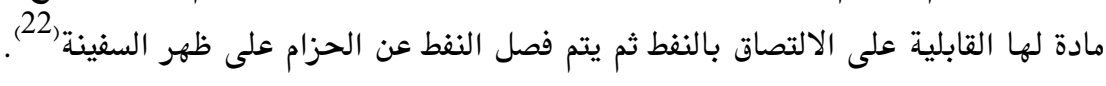

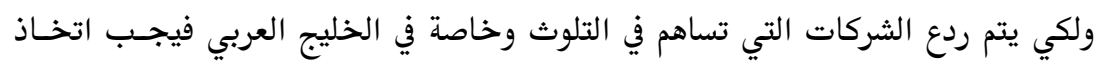
قوانين في هذا السياق تعرف بالقوانين البيئيـة والدذي عرفهـا مـؤتمر سـتوكهولم للبيئسة بأنسه

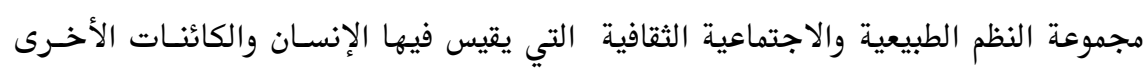
والتي يستمدون منها زادهم ويؤدون فيها نشاطاتهمج"23.

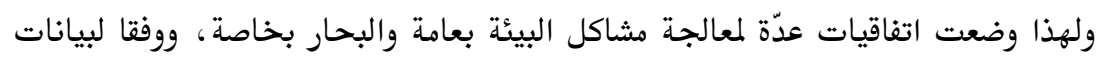

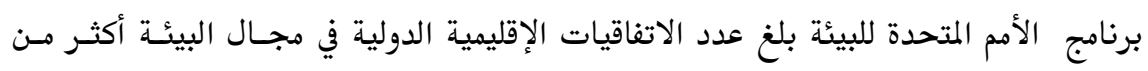

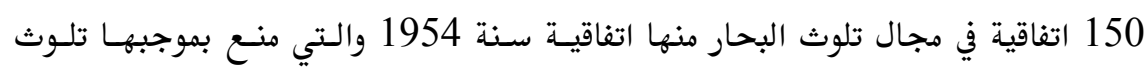

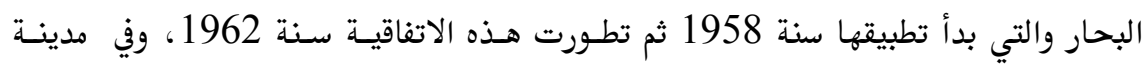

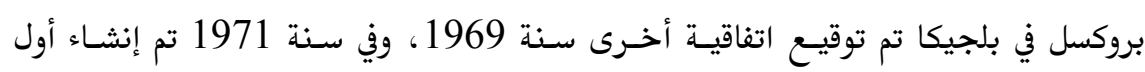

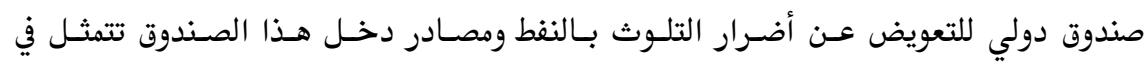


اشتراكات الجهات المستوردة للنفط في البلدان المنظمة لهذه الاتفاقية، كمـا عُقـد مـؤتمر الأمسم

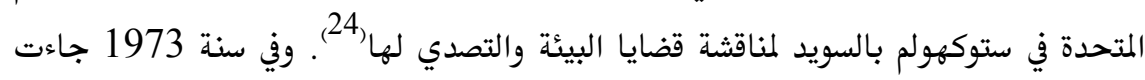

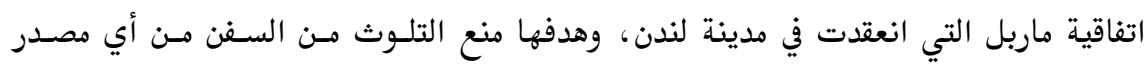

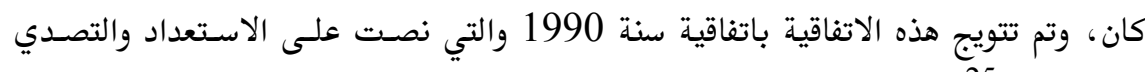
لمنع التلوث(25)، ومن أشهر الاتفاقيات ذات العلاقة لحمايـة البيئسة البحريـة اتفاقيـة الأمسم

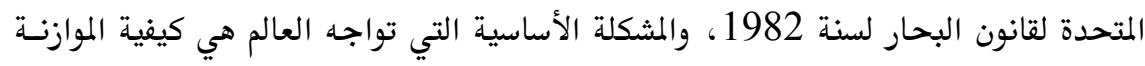

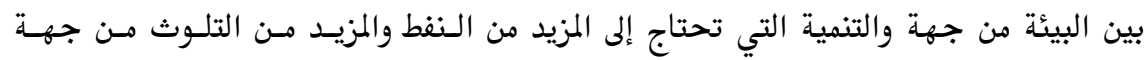

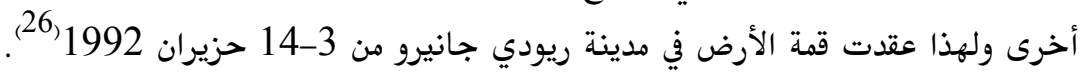

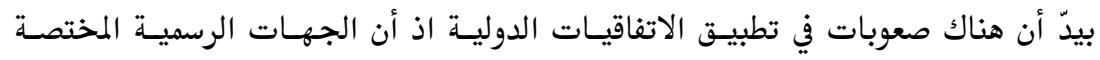

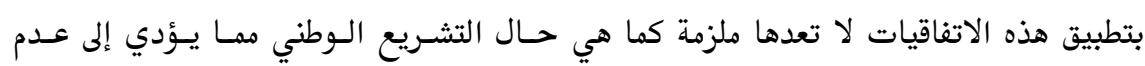
الاستفادة منها ولهذا تم تشريع قوانين وطنية، فلقد اقر مجلس التعاون لبلدان الخليج العربي لئي

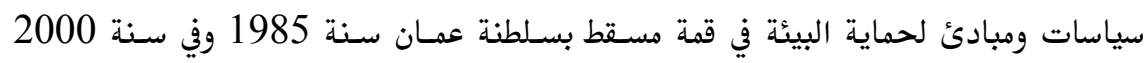

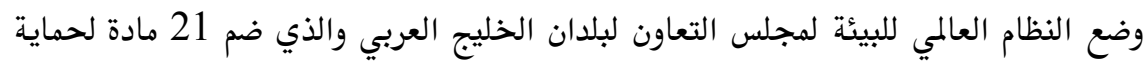

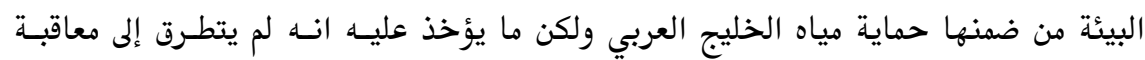

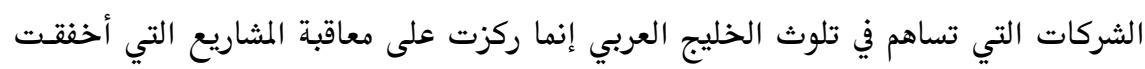

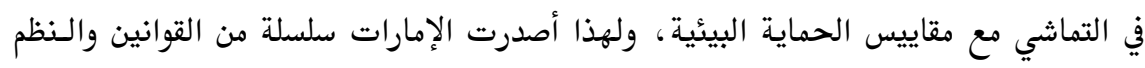

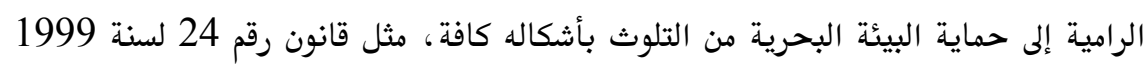

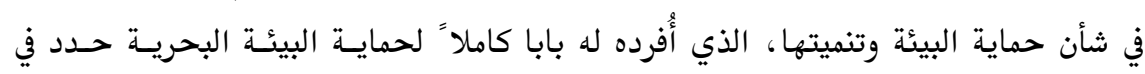

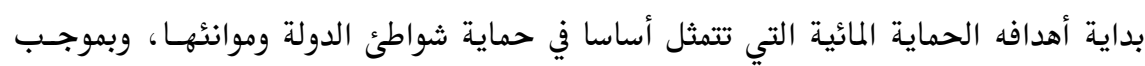

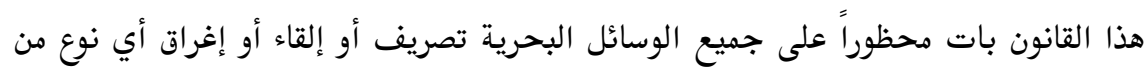

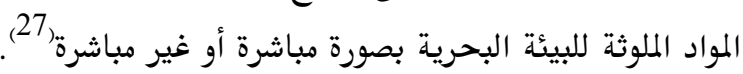

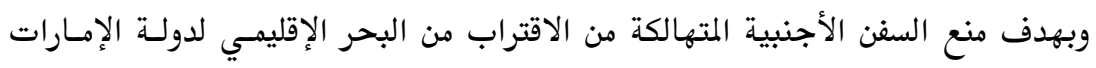

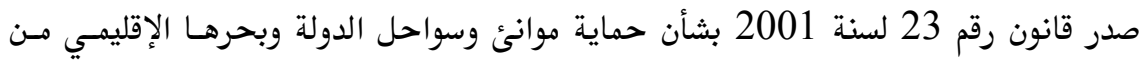

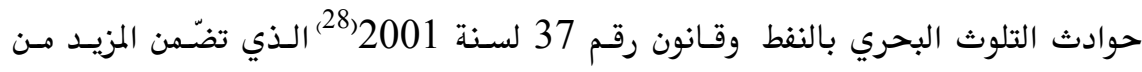
الضوابط والإجراءات الرامية إلى حمايـة البيئـة البحريـة، كمـا اقر القـانون رقـم 29 لسـنة 


$$
\text { عبدالناصر صبحي }
$$

2006 والذي حظر استخدام السفن وجميـع أنسواع الوحسدات البحريـة بمـا فيهـا الصنادل

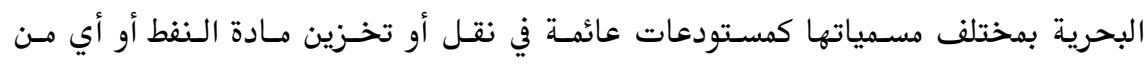

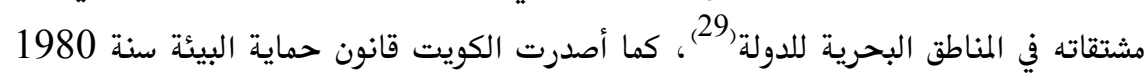

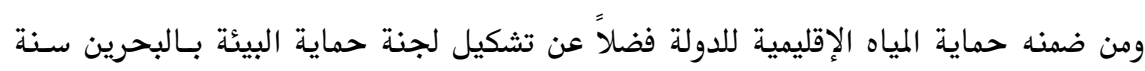

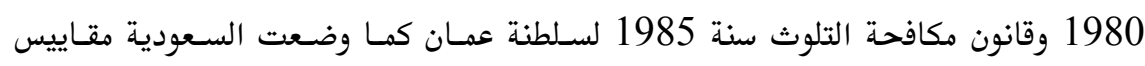

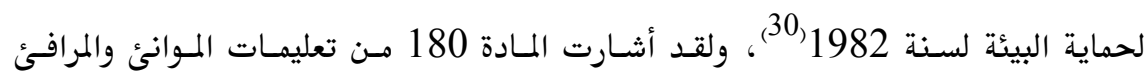
العراقية رقم (1) لسنة 1998 إلى أنه (عند الـتخلص مسن الـنفط أو الزيـت أو الميـاه الملوثـة

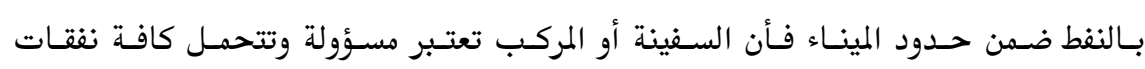
التنظيف)(31).

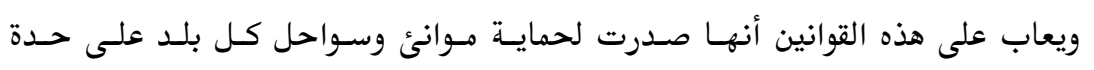

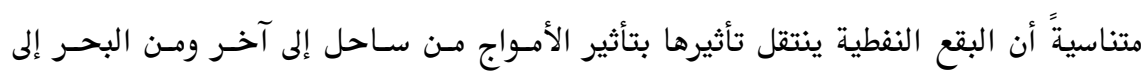

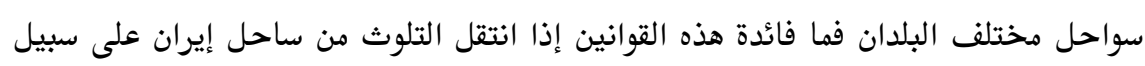

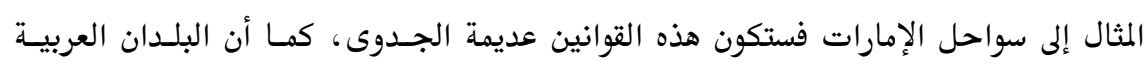

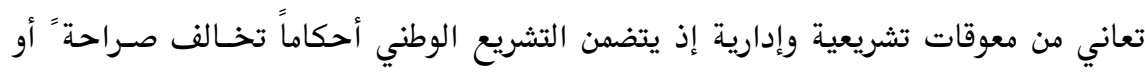

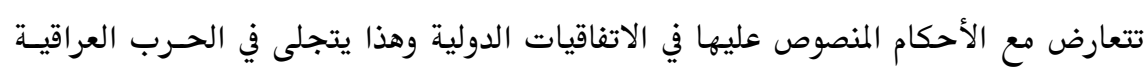

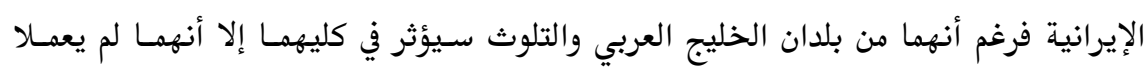

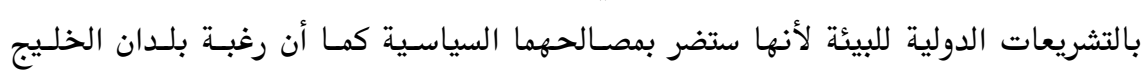
بالتنمية الاقتصادية جعلها لا تهتم بتطبيق الاتفاقيات الدولية المصادق عليها.

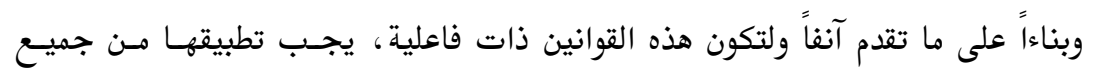

$$
\text { البلدان المطلة على الخليج العربي. }
$$

ولخطورة تلوث البحر بالنفط نلاحظ أن الكيان الصهيوني رغم انه لا ينتج الـنفط إلا انسه

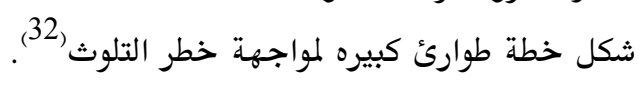

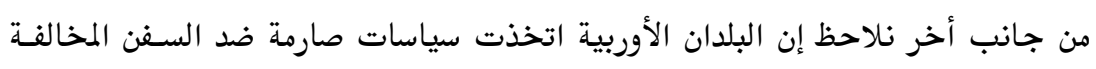

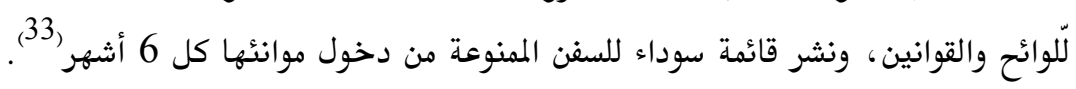


المبحث الرابع: الاستشراف المستقبلي لحجم التلوث وتكاليف التنظيف في الخليج العربي هناك عوامل عدة تؤثر في تكلفة تنظيف التسرب النفطي منها المنطقة المتسرب فيها ومدى

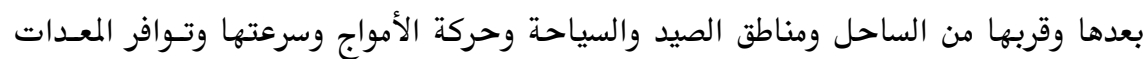

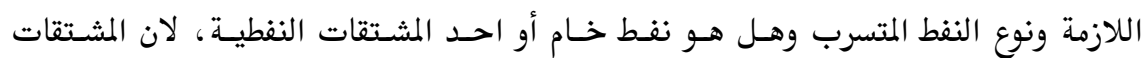

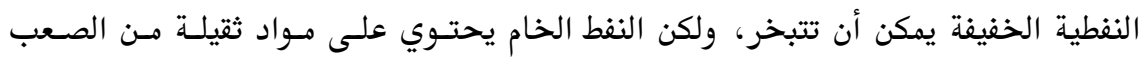

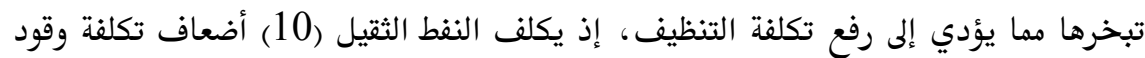

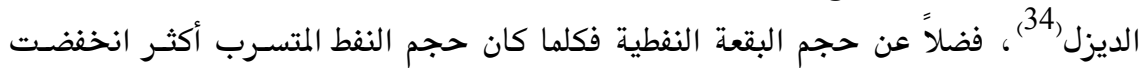

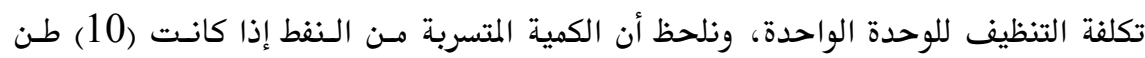

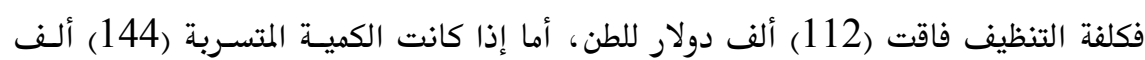
طن فان تكلفة التنظيف هي (667) دولار للطن انظر الجدول (3). الجدول (3) تكاليف تنظيف بعض الحوادث النفطية

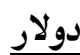

\begin{tabular}{|c|c|c|c|c|}
\hline تكلفة تنظيف الطن & إجمالي تكاليف & كمية النفط & السنة & اسم السفينة \\
\hline 112230 & 1122301 & 10 & 1979 & Tarpenbek \\
\hline 150000 & 6000000 & 40 & 1995 & Yeo my ung \\
\hline 750000 & 15000000 & 200 & 1993 & Lliad \\
\hline 71000 & 13189000 & 185 & 1990 & Rio crinoco \\
\hline 729 & 60000000 & 72360 & 1996 & Sea empress \\
\hline 823 & 60500000 & 73500 & 1992 & Aegeab sea \\
\hline 714 & 60000000 & 84000 & 1993 & Braer \\
\hline 667 & 96000000 & 144000 & 1991 & Itaven \\
\hline
\end{tabular}

المصدر: احتسبت باستخدام المصادر التالية:

Catherine J, Grey, The cost of oil pills from tankers an analysis of opec fund incidents , 1999, p.14

Itopf ,com/spill-compensation/cost-of-spills 
إن استمرار تلوث النفط بالمعدل الحالي سيقود إلى كارثة بيئية حقيقية في الخليج العربي،

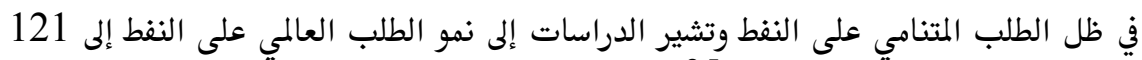

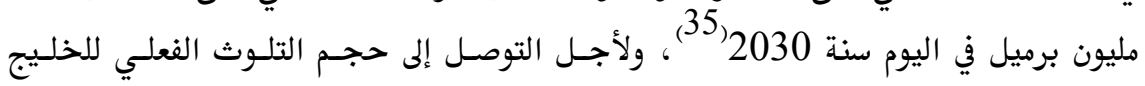

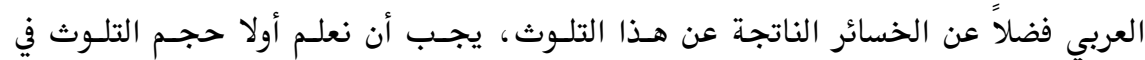

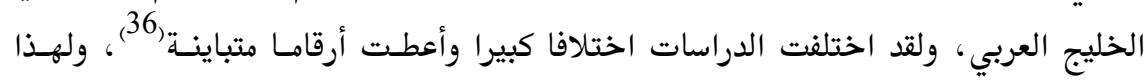

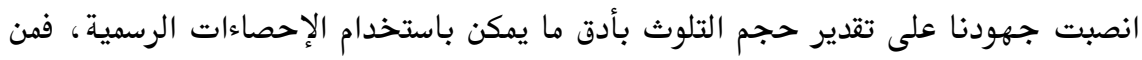

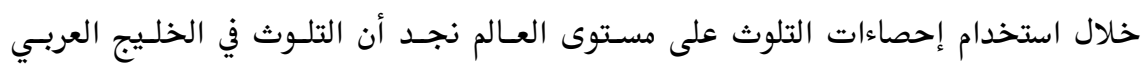

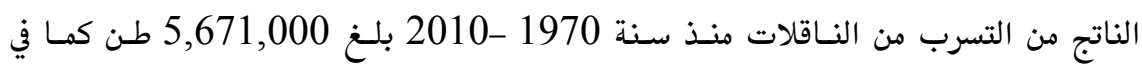

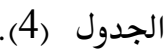

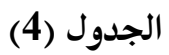

حجم التلوث النفطي في العالم بسبب الناقلات للمدة 1970-2010 ط

\begin{tabular}{|c|c|c|c|c|c|c|c|}
\hline الكمية & السنة & الكمية & السنة & الكمية & السنة & الكمية & السنة \\
\hline 14,000 & 2000 & 61,000 & 1990 & 206,000 & 1980 & 330,000 & 1970 \\
\hline 8,000 & 2001 & 430,000 & 1991 & 48,000 & 1981 & 138,000 & 1971 \\
\hline 67,000 & 2002 & 167,000 & 1992 & 12,000 & 1982 & 297,000 & 1972 \\
\hline 42,000 & 2003 & 140,000 & 1993 & 384,000 & 1983 & 164,000 & 1973 \\
\hline 15,000 & 2004 & 130,000 & 1994 & 29,000 & 1984 & 174,000 & 1974 \\
\hline 18,000 & 2005 & 12,000 & 1995 & 85,000 & 1985 & 355,000 & 1975 \\
\hline 23,000 & 2006 & 80,000 & 1996 & 19,000 & 1986 & 398,000 & 1976 \\
\hline 18,000 & 2007 & 72,000 & 1997 & 30,000 & 1987 & 291,000 & 1977 \\
\hline 2,000 & 2008 & 15,000 & 1998 & 190,000 & 1988 & 352,000 & 1978 \\
\hline 1,000 & 2009 & \multirow{2}{*}{29,000} & \multirow{2}{*}{1999} & \multirow{2}{*}{174,000} & \multirow{2}{*}{1989} & \multirow{2}{*}{641,000} & \multirow{2}{*}{1979} \\
\hline$\cdot 10,000$ & 2010 & & & & & & \\
\hline
\end{tabular}

Itopf, oil tanker spill statistics : 2009, p.3 
إذ نستطيع ان نستنتج حجم التسرب من العوامل الأخـرى، لان التسـرب مسن النـاقلات يمثل 65,4 بالمئة من إجمالي التسرب، كما مبين في جدول (5).

(5) الجدول

نسب وكمية النفط المتسرب بحسب السبب لبلدان العالم

\begin{tabular}{|c|c|c|c|}
\hline الكمية (برميل) & الكمية (طن) & نسب التسرب & أسباب تسرب النفط \\
\hline $41,568,000$ & 5671,000 & 65,4 & حوادث اصطدام جنوح \\
\hline $13,025,000$ & $1,777,000$ & 20,5 & حوادث + فشل تحميل \\
\hline $4,573,000$ & 624,000 & 7,2 & إطلاق نار \\
\hline $4,383,000$ & 598,000 & 6,9 & أخرى غير معروفة \\
\hline
\end{tabular}

المصدر: - احتسبت بالاعتماد على المصدر

Itopf, oil tanker spill statistics : 2010, p. 6

وبمـا أن نسـبة صـادرات البلـدان العربيـة الى العـالم هي 31\% في المتوسط إذا يمكـن

استخراج نسبة حوادث التسرب في الخليج العربي كما في الجدول (6).

الجدول (6)

كمية النفط المتسرب حسب السبب لبلدان الخليج العربي للمدة

2010-1970

\begin{tabular}{|c|c|}
\hline الكمية (برميل) & أسباب التلوث \\
\hline $13,409,000$ & حوادث ناقلات \\
\hline $4,201,000$ & تحميل تغريغ (فشل تحميل ) \\
\hline $1,476,000$ & إطلاق نار \\
\hline $1,413,000$ & أخرى غير معروفة \\
\hline
\end{tabular}




\begin{tabular}{|r|r|}
\hline التسرب النفطي نتيجة حرب الخليج 1991 \\
\hline المجموع & \\
\hline
\end{tabular}

المصدر:- احتسبت القيم بالاعتماد على الجدول (5).

Itopf, oil tanker spill statistics: 2010, p. 6

إذاً إجمالي النفط المتسـرب مـن الأسباب المختلفـة 31,499 مليـون برميـل، وبإضـافة

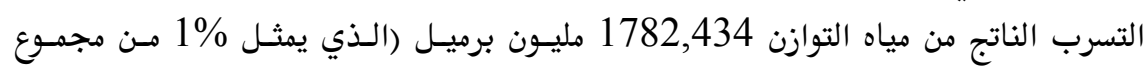

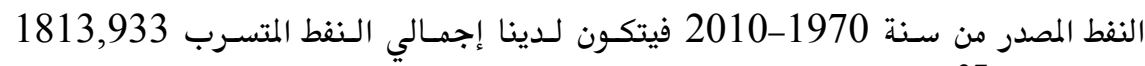

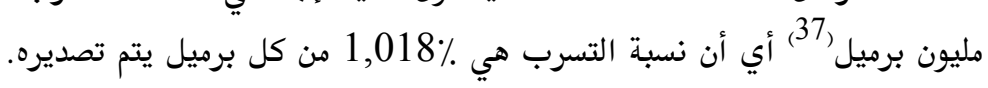

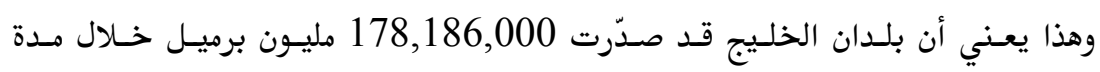

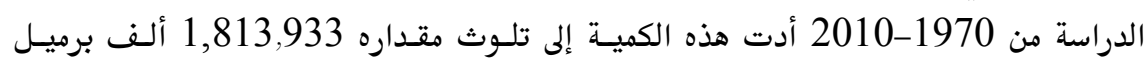

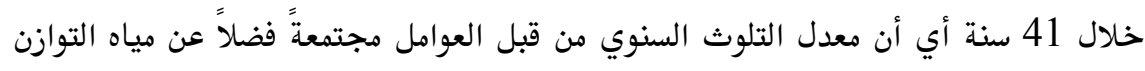

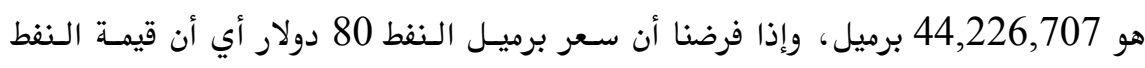

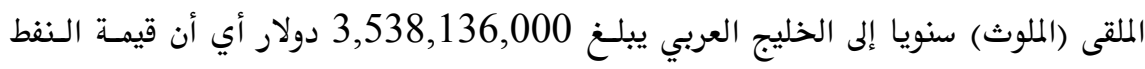

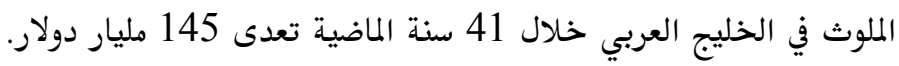
الجدول (7) كمية النفط المتسرب من صادرات بلدان الخليج العربي الماضية تعدى دالئ

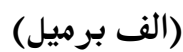

\begin{tabular}{|c|c|c|c|c|}
\hline كمن الصادرات للنفط المتسرب & بلدبة صادرات إجمالي صادرات كل بلد & من النفط المصدر & من النفط المنتج & البلد \\
\hline 260,680 & 14,37 & $25,607,000$ & $26,361,000$ & الامارات \\
\hline 649,556 & 35,82 & 63807,000 & $112,486,000$ & السعودية \\
\hline 211,784 & 11,68 & $20,804,000$ & $27,501,000$ & العراق \\
\hline 70,903 & 3,89 & $6,965,000$ & $6,646,000$ & قطر \\
\hline 180,318 & 9,94 & $17,713,000$ & $26,621,000$ & الكويت \\
\hline 44,692 & 24,30 & $43,347,000$ & $53,628,000$ & ايران \\
\hline 1813,933 & 100 & $178,243,000$ & المجموع & \\
\hline
\end{tabular}


دراسات إقليمية 8 (24)

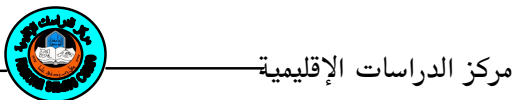

Organization of petroleum exporting countries , annual statistical review, 1979, 2000, 2008

* تم احتساب كمية النفط المتسرب لكل بلد اعتمادا على صـادراتها رغـم اخـتلاف التلـوث مـن بلـد لأخـر وذلكك لاشتراكهم جميعا في مياه الخليج العربي.

وإذ استمر التلوث في الخليج العربي على ما هو عليه فيمكن أن تبلغ كمية النفط المتسرب في ضوء الخزين لبلدان الخليج العربي 7,548,266 ألف برميل انظر الجدول (8). ومن خلال حجم الخزين المثبت لدى بلدان الخليج العربي الذي يبلغ 741,388 مليون برميل يتبين لنا أن حجم التلوث المستقبلي سـيبلغ 7548 مليـون برميـل إذا استمر حجـم

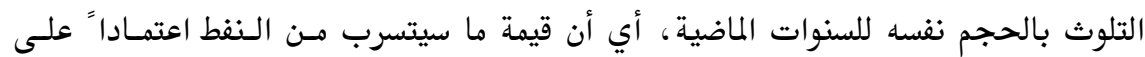
الخزين سيقرب من 604 مليار دولار عند سعر 80 دولار للبرميل انظر الجدول (8). الجدول (8) حجم النفط المتوقع تسربه وقيمته قياساً لحجم الاحتياطي المؤكد

(ألف برميل)

\begin{tabular}{|c|c|c|c|}
\hline 80 قيمة النفط المتوقع تسربـه & كمية النفط المتوقع & احتياطي النفط المثبت لبلدان & البلد البل \\
\hline 79,658 & 995,727 & $97,800,000$ & الإمارات \\
\hline 215,080 & $2,688,495$ & $264,063,000$ & السعودية \\
\hline 93,668 & $1,170,845$ & $115,000,000$ & العراق \\
\hline 20,692 & 258,655 & $25,405,000$ & قطر \\
\hline 82,672 & $1,033,398$ & $101,500,000$ & 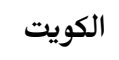 \\
\hline 112,091 & $1,401,146$ & $137,620,000$ & إيران \\
\hline 603,861 & $7,548,266$ & $741,388,000$ & \\
\hline
\end{tabular}

المصدر: احتسب اعتماداً على مصدر الجدول السابق.

Organization of petroleum exporting countries, annual statistical review, 1979, 2000, 2008. 


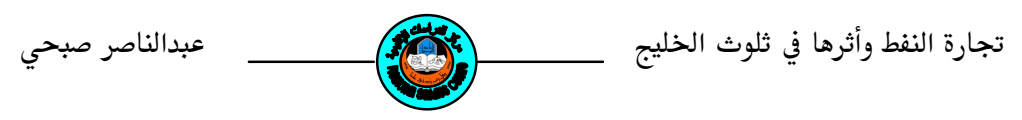

ولا يجب أن نتناسى حقيقة ههمة وهي تكاليف تنظيف البقع النفطية التي هي أضعاف

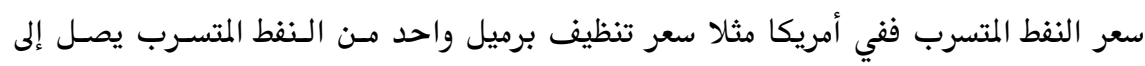
42 ألف دولار (18). ولكن ما هي تكلفة تنظيف تسرب النفط في الخليج العربي؟

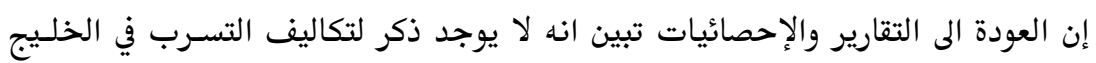

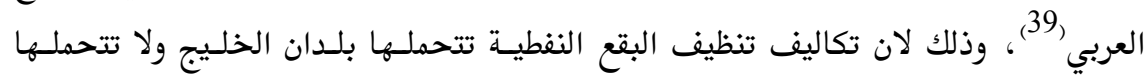

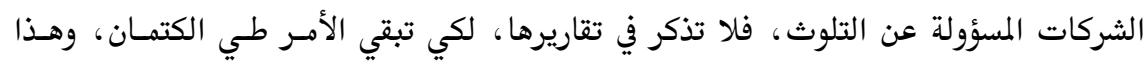

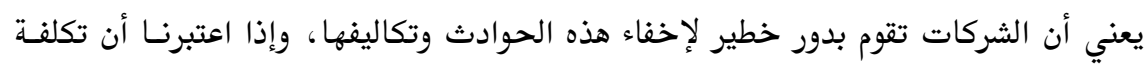

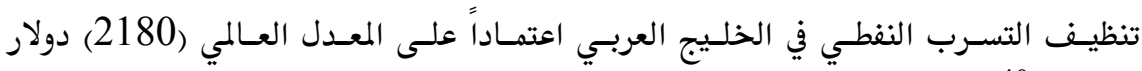

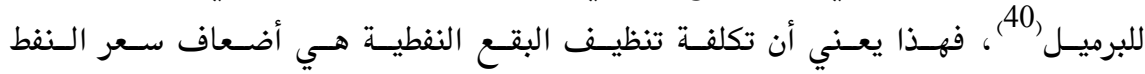

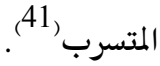

بعبارة أخرى إذا استمر التلوث لما هو عليه وأردنا أن نعالج هذا التلوث عن طريق تنظيف

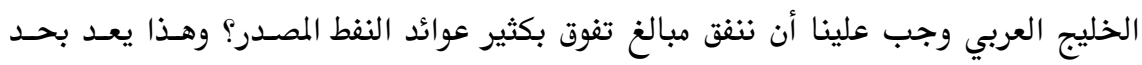
ذاته كارثة اقتصادية تضاف إلى الكارثة البيئية. 


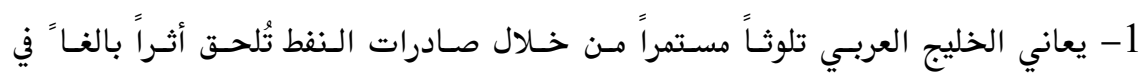

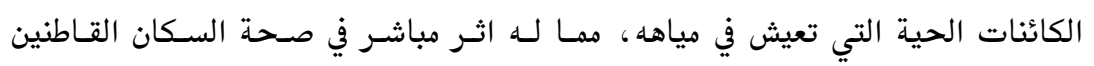
بجواره.

2- هناك العديد من الاتفاقيات المبرمة على المستوى الدولي والمحلي إلا انه يوجد تراخي في تنفيذ الاتفاقيات الدولية والمحلية.

3- إن أهم عامل للتلوث في الخليج العربي هو التسرب نتيجة مياه التوازن يعقبها في الأهمية التسرب من حوادث الناقلات والحروب.

4- إذا استمر التلوث على ما هو عليه فان قيمة النفط المتوقع تسربه في ضوء الخزين المثبـت

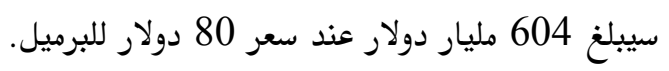

التوصيات

1- يجب تطبيق الاتفاقيات الدولية والاتفاقيات على المستوى المحلي لجميع البلدان بـدون

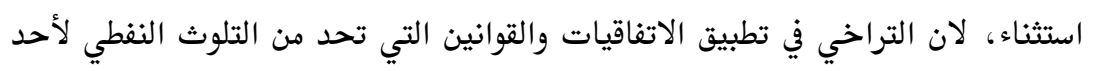

بلدان المنطقة سيؤدي إلى تعرض جميع البلدان المطلة على الخليج العربي للتلوث.

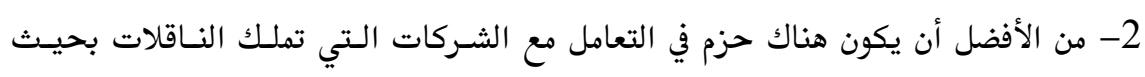

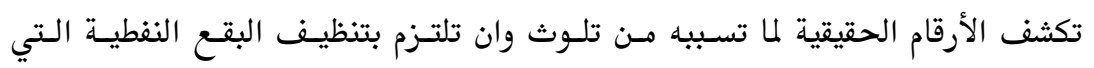

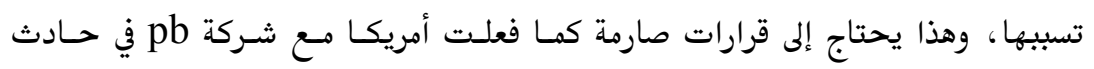
تسرب من بئر نفطي أمام السواحل الأمريكية.

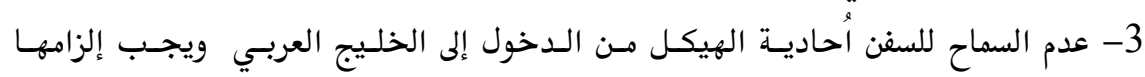
بتفريغ مياه التوازن خارج مياه الخليج العربي.

\section{Trade of oil and impact in the Arabic Gulf pollution}




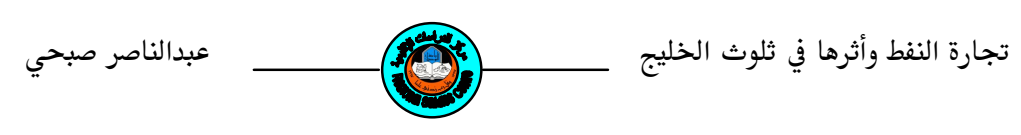

Mtbded Sassen Traahim Qbobi

Mssistant Qfecturer, college of administration and EConomics, Olniversily

of Mboul

\begin{abstract}
Area is Arabic Gulf of the most important centers for the production of oil and stocks strategic global, making it one of the most polluted areas in the world, as the cause of this pollution raised the toll in human and animal, and I have been addressing this pollution by using several techniques, as well as legislation of laws to reduce pollution but that the factors contaminated, most notably water leakage through the balance will lead to the outbreak of serious risks, especially with the presence of more than $57 \%$ of the world's proven oil reserves in the countries of the Arabic Gulf.
\end{abstract}




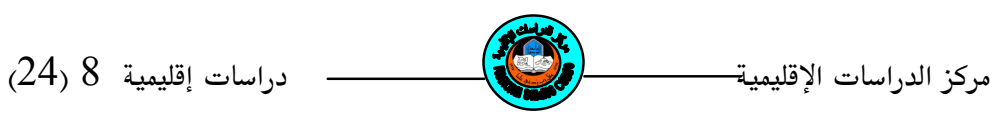

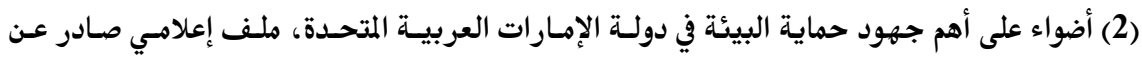

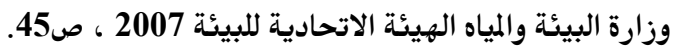

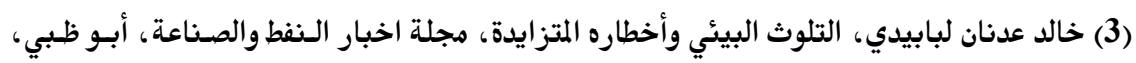

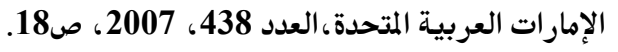

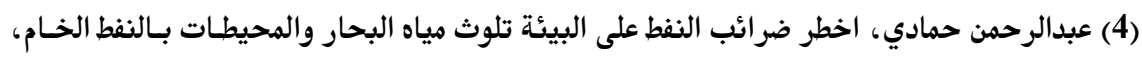

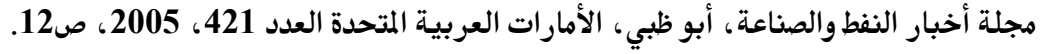

(5) www. uaeec.com /news - action -show - id - 12189. htm

$$
\text { (6) عبدالرحمن حمادي، مصدر سابق، ص12. }
$$

(7) World Trade Organization ,International Trade Statistics, 2010, p. 59.

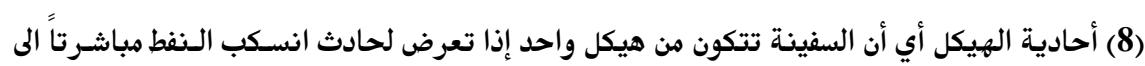

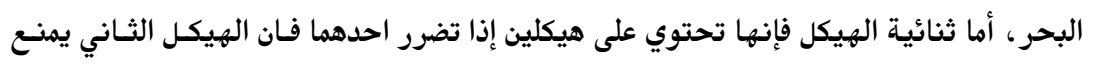

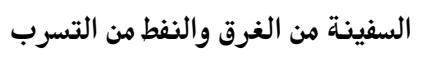

(9) بشير محمد هوساوي، الخليج العربي والتلوث بـالنقط، برنـامج ماجستير مقدم إلى كليـة العلـوم،

$$
\text { السعودية، 2007، صحمد موساوي، الخليج }
$$

(10) ديفيد واسكو وكارول ويلش ، آثار صناعة النفط على البيئـة والمجتمع وحقوق الإنسان ، معهـد

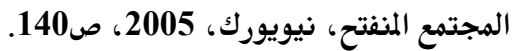

$$
\begin{aligned}
& \text { (11) بشير محمد هوساوي، مصدر سابق، صنئ }
\end{aligned}
$$

(12) http://science. jrank.org / pages / 4848 / oil - spills - oil - pollution.html (13) عبدالله عيسى دباغ وآخرون، الحد من التلوث الناشئ عن بقع الزيت وحرائق أبار الدبترول أثنـاء

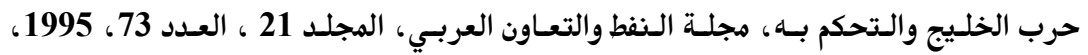

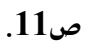

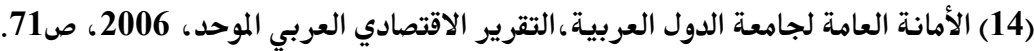

(15) استخرجت من قبل الباحث بالاعتماد على مصادر الجدول (6) (6).

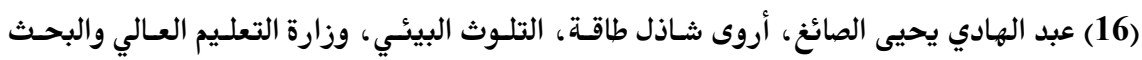

$$
\begin{aligned}
& \text { العلمي، بغداد، 2002، ص177 } \\
& \text { للمزيد من الاطلاع انظر : بغلي }
\end{aligned}
$$

Bp: shipping environmental statement: 2006. p.27

(17) المصدر نفسه، ص178-179.

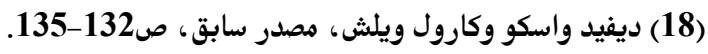




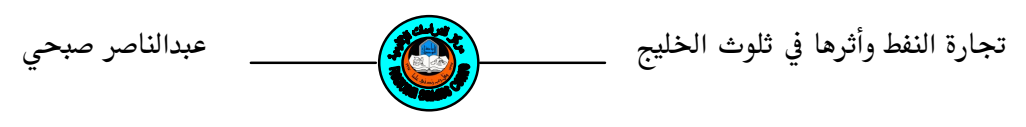

$$
\text { (19) عبدالرحمن حمادي، مصدر سابق، ص11. }
$$

(20)www.islamonline.net

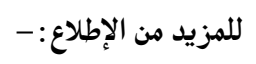

دوناتو رومانو ، الاقتصاد البيني والتنمية المستدامة، وزارة الزراعة والإصلاح الزراعي ، سوريا، 2003

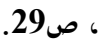

(21) Nasser Al hasher, sofia tahseen, prevention United Nations of Oil spill pollution in seawater using locally available materials. the Arabian journal for sciences and engineering, October 2005. p.146

$$
\text { (23) عبدالهادي يحيى الصائغ، أروى شاذل طاقة، مصدر سابق، ص188. }
$$

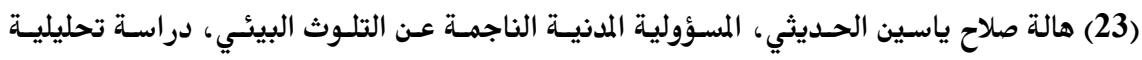

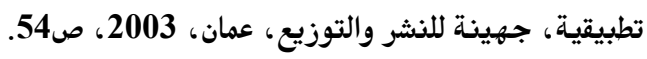

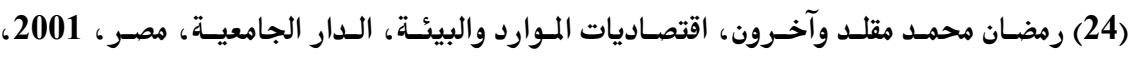

$$
\text { ص347. }
$$

(25) عبدالرحمن حمادي ، مصدر سابق، ص14.

$$
\text { للمزيد من الإطلاع:- }
$$

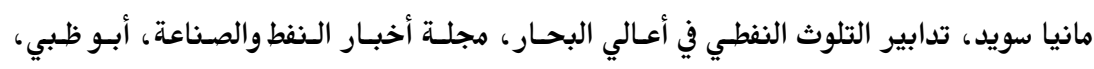

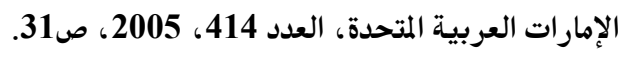

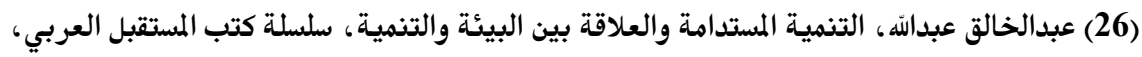

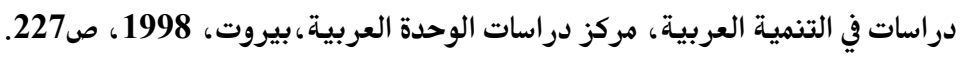

(27) النظام العام للبيئة لمجلس التعاون لدول الخليج العربية الصادر بالمرسوم الملكي رقـم م / 3 لسـنة

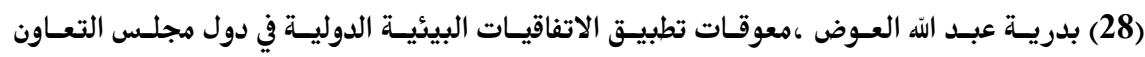

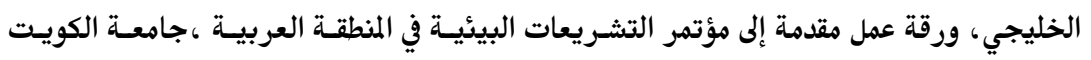

$$
\text { الحزي }
$$

$$
\text { للمزيد من الإطلاع على القانون انظر: - }
$$

قرار مجلس الوزراء رقـم (37) لسـنة 2001، نظـام حمايـة البيئـة البحريـة، امـارة دبـي، لسـنة

(29) أضواء على أهم جهود حماية البيئة في دولة الإمارات العربيـة المتحسدة، ملف إعلامي صـادر عـن

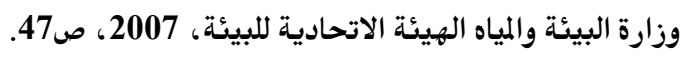




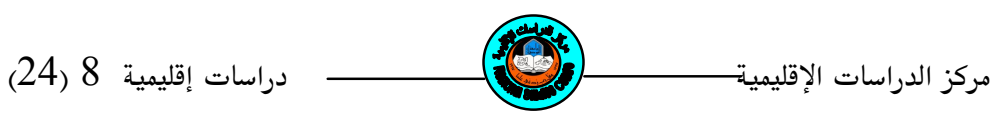

(30) التنميـة الاقتصـادية والاجتماعيسة لغربسي أسـيا، الاسـتدامة البيئسة الحضـرية، الأمسم المتحـدة،

نيويورك، 2001 ص29.

52 (31) هالة صلاح ياسين الحديثي، مصدر سابق، صورك،

(32) Ministry of the environment national assessment, implementing agenda 21 in Israel, Jerusalem, march, 2005. pp. 76-80

$$
\text { : (33) للمزيد من الإطلاع }
$$

United Nations General Assembly Oceans and the law of the of the sea, report of the secretary - General, 20 march 2000, p.17

(34) United Nations -offshore petroleum exploitation and international low, the Nippon foundation of Japan fellow ship program me, 2007-2008 p.3

$$
\text { للمزيد من الإطلاع : }
$$

Opec pollution fourth opec inter national seminar a preview, 2009, p.17

(35) Dagmar Schmidt Etkin , ESTIMATING CLEANUP COSTS FOR OIL

SPILLS, Oil Spill Intelligence Report, 1999, P4

$$
\begin{aligned}
& \text { (36) إن الشركات العالمية تخفي حجم التلوث الحقيقي لكي تتفادى مبالغ التعويضات بسـبب الخسـائر } \\
& \text { الناتجة عن الإضرار بالبيئة. } \\
& \text { (37) وهذا يعني أن مياه التوازن مسئولة عن 98\% من إجمالي التلوث في الخليج العربي }
\end{aligned}
$$

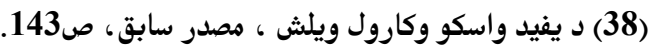

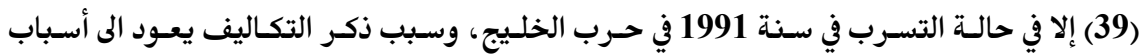

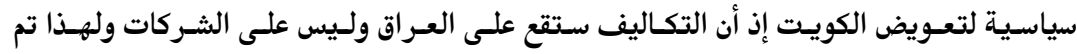

$$
\begin{aligned}
& \text { احتساب تكاليف التنظيف. }
\end{aligned}
$$

(40) www.myprojectspace,eu

(41) لان حجم التلوث المستقبلي إذا استمر على السوتيرة نفسهها سـيبلغ 7548 مليسون برميل، ونحتـاج لتنظيف هذا التسرب إلى أكثر من 16 ألف مليار دولار. 